\title{
Oxidative Shielding or Oxidative Stress?
}

\author{
Robert K. Naviaux
}

The Mitochondrial and Metabolic Disease Center, Departments of Medicine, Pediatrics, Pathology, University of California, San Diego School of Medicine, 214 Dickinson St., Bldg CTF, Rm C102, San Diego, CA 92103-8467 


\section{Running Title Page}

Running Title: $\quad$ Oxidative Shielding

Author: $\quad$ Robert K. Naviaux

Address: $\quad$ University of California, San Diego School of Medicine, 214 Dickinson St., Bldg CTF, Rm C102, San Diego, CA 92103-8467. EMAIL: Naviaux@ucsd.edu. Phone: 619543-2904. Fax: None

ABSTRACT WORDS: $\quad 240$

TEXT PAGES: $\quad 21$

TEXT WORDS: $\quad 6,710$

INTRODUCTION: $\quad 540$

DISCUSSION: $\quad 429$

FIGURES: $\quad 3$

TABLES: $\quad 1$

REFERENCES: 75

Non-standard abbreviations:

GYA: giga years ago $\left(10^{9}\right.$ years ago $)$

$\Delta \mathrm{G}$ : Change in Gibbs chemical free energy (Products - Reactants)

kPa: $\quad$ kilo Pascals; $101.3 \mathrm{kPa}=760 \mathrm{~mm} \mathrm{Hg}$ (Torr) $=1$ atmosphere of pressure

Torr: millimeters of Mercury pressure $(\mathrm{mm} \mathrm{Hg})$ 


\section{JPET \#192120 PiP}

\section{ABSTRACT}

In this review I report evidence that the mainstream field of oxidative damage biology has been running fast in the wrong direction for over 50 years. Reactive oxygen species (ROS) and chronic oxidative changes in membrane lipids and proteins found in many chronic diseases are not the result of accidental damage. Instead, these changes are the result of a highly evolved, stereotyped, and protein-catalyzed "oxidative shielding" response that all eukaryotes adopt when placed in a chemically or microbially hostile environment. The machinery of oxidative shielding evolved from pathways of innate immunity designed to protect the cell from attack and to limit the spread of infection. Both oxidative and reductive stress trigger oxidative shielding. In the cases in which it has been studied explicitly, functional and metabolic defects occur in the cell before the increase in reactive oxygen species (ROS) and oxidative changes. ROS are the response to disease, not the cause. Therefore, it is not the oxidative changes that should be targeted for therapy, but rather the metabolic conditions that create them. This fresh perspective is relevant to diseases that range from autism, Type 1 diabetes, Type 2 diabetes, cancer, heart disease, schizophrenia, Parkinson's disease and Alzheimer disease. Research efforts need to be redirected. Oxidative shielding is protective and is a misguided target for therapy. Identification of the causal chemistry and environmental factors that trigger innate immunity and metabolic memory that initiate and sustain oxidative shielding is paramount for human health. 
Nothing in biology makes sense except in the light of evolution.

Theodosius Dobzhansky (1973)(Dobzhansky, 1973)

\section{INTRODUCTION}

An alternative title for this review might be, "Oxidative Stress or Oxidative Shielding-Can 50 Years of Research be Wrong?" To understand why cells might choose to defend themselves from harm by intentionally making reactive oxygen species like superoxide and hydrogen peroxide, and by stiffening the cell membrane to make it less permeable and less vulnerable to attack, we need to start at the beginnings of life on our planet. The great evolutionary pulses of metabolic and structural innovation of life on Earth can be correlated with changes in environmental oxygen(Holland, 2006). In the beginning, all life on Earth was anaerobic and oxygen was toxic. The first cells to emerge in the Precambrian seas were anaerobic bacteria that made ATP by anoxygenic photosynthesis. This life chemistry dates to about 3.5 billion years ago (GYA)(Yang et al., 2009). Most of the pathways of intermediary metabolism that we know today were developed during this anaerobic epoch of life's history on Earth. Isoprenyl and ubiquinol synthesis, fatty acid oxidation and synthesis, iron-sulfur cluster synthesis, glycolysis, carotenoid synthesis, the pentose phosphate pathway, the glyoxylate cycle, pyruvate dehydrogenase, cobalamin synthesis, heme synthesis, cytochromes, glutathione metabolism, electron transport, chemiosmotic proton-coupling for ATP synthesis, and both reductive and oxidative (reverse, and forward) Krebs cycles were all present in the oldest bacteria known, the green sulfur bacteria(Tang and Blankenship, 2010). These and other bacterial primary producers fixed carbon from $\mathrm{CO}_{2}$, fertilized the seas with organic molecules that later became the food, and created the genetic tool kit for intermediary metabolism upon which all later life was based.

Oxygen came late on the scene. Beginning about 2.4 billion years ago, cyanobacteria started producing oxygen from photosynthesis in sufficient quantities to ventilate shallow seas and to raise atmospheric oxygen levels to about 2-4\%(Rasmussen et al., 2008; Hohmann-Marriott and 
Blankenship, 2011). This value of 2-4\% oxygen (0.02-0.04 atm; $2-4 \mathrm{kPa} ; 15-30 \mathrm{Torr},(\mathrm{mm} \mathrm{Hg}$ partial pressure) assuming an atmospheric pressure of 760 Torr at sea level) corresponds to about 20-40 $\mu \mathrm{M}$ of dissolved oxygen in shallow, well-mixed Precambrian seas. This is very close to the partial pressure of oxygen of most mammalian tissues at the end of capillary beds today, and is also very close to the saturation midpoint (p50) of hemoglobin A of 28 Torr(Winslow, 2007). The first single-celled eukaryotes with mitochondria may have emerged as early as 1.7-1.1 GYA(Knoll et al., 2006; Brinkmann and Philippe, 2007). The p50 of modern mitochondria for oxygen in state 4 respiration is 0.2 Torr $(0.025 \mathrm{kPa})$, or about $0.3 \mu \mathrm{M}(\mathrm{Gnaiger}$ et al., 1995). This creates a natural 150-fold oxygen gradient from ambient concentrations of 30 Torr outside the cell to 0.2 Torr at the site of oxygen consumption by the enzyme cytochrome $\mathrm{c}$ oxidase in each mitochondrion. These ancestral plant and animal cells were dispersed by the winds and tides as plankton, finding chemically unique niches, specializing, and sharing the Precambrian seas with bacteria and viruses. This rich ecology coevolved for a billion years before multicellularity took hold and expanded during the Cambrian around 0.54 GYA. Much of modern metabolism that is aimed at utilizing or taming oxygen, and to give it teeth in a fight was developed during this pivotal Precambrian epoch. The free radical theory of aging was proposed by (Harman, 1956).

\section{Self-defense is Nature's oldest law. John Dryden (1681)}

\section{Mitochondria, Innate Immunity, and Cellular Defense}

In this review I present evidence that one of the most ancient functions of mitochondria was cellular defense. Today we call this metabolic response to cellular attack or injury "innate immunity". Mitochondria play a central role in innate immunity today(West et al., 2011). This is the direct result of the role that bacterial ancestors or mitochondria played in the Earth's early oceans. The complex ecology of the Precambrian seas was replete with viruses and predatory intracellular bacteria(Wichels et al., 1998). No cells without effective defenses survived. The 
biochemical signature of an attack is a metabolic "steal" or diversion of electrons and resources like nitrogen, phosphorus, iron, and copper. When limiting cellular resources are utilized by predators and parasites, those resources are not available to the host cell. Mitochondria are uniquely equipped to detect and respond to this metabolic steal. When the local chemistry of the cell provides nutrients and resources in concentrations that are matched to mitochondrial metabolism, mitochondria will create a normal oxygen gradient of about 30 outside the cell to 0.2 Torr in the mitochondrial matrix(Gnaiger et al., 1995) (see above). When cellular resources are consumed by a parasite, a "metabolic mismatch" is produced.

Mitochondria have a proteome of about 1500 proteins(Pagliarini et al., 2008). Nearly 1000 of these proteins have catalytic functions in cell metabolism, like citrate synthase, or malate dehydrogenase. Under normal physiologic conditions, the concentrations of thousands of nutrients and metabolic substrates in mitochondria are closely governed by the collective kinetic constants (Km, Kcat, Vmax, Hill Coefficient, etc) of all the enzymes responsible for transforming those metabolites. This has recently been computationally modeled in the Recon 1 and BiGG reconstructions of cell and organ metabolism(Schellenberger et al., 2010; Rolfsson et al., 2011). Only the primary structure of an enzyme is genetically determined. The activity of an enzyme at any instant in time is determined by ambient metabolic conditions. For example, the $\mathrm{Km}$ of citrate synthase for oxaloacetate is about $2 \mathrm{mM}$, but the enzyme is allosterically inhibited by ATP, NADH, Acetyl-CoA, Palmitoyl-CoA, and the product citric acid, so the rate of converting oxaloacetate to citrate is changing minute-to-minute according to the condition of the cell(Shepherd and Garland, 1969). When the concentrations of substrates are perturbed by viral or microbial infection, disease, toxin, or nutritional excess, mitochondria sense this as a metabolic mismatch between the optimum concentration of those metabolites for a given tissue, and the actual concentration. 


\section{JPET \#192120 PiP}

This metabolic mismatch diverts electron flow away from mitochondria in the cell, decreases intramitochondrial electron flow, and mitochondrial oxygen consumption falls. When mitochondrial oxygen consumption (extraction) falls and the cell is still surrounded by 30 Torr (24\%) oxygen supplied by capillaries, the concentration of oxygen in the cell rises sharply. When cellular oxygen rises, the redox of the cell rises, and the chemistry of polymer assembly (DNA, RNA, lipid, protein, and carbohydrate synthesis) is ultimately stopped because the $\mathrm{NADPH} / \mathrm{NADP}+$ ratio falls an the change in Gibbs chemical free energy $(\Delta \mathrm{G})$ of synthetic reactions becomes less negative (more positive $\Delta G$ are thermodynamically less favorable). Under these more oxidizing conditions, electrons are no longer available for carbon-carbon bond formation to build biomass for viral or intracellular bacterial replication. Electrons are instead abstracted by the rising tide of intracellular oxygen to make superoxide, other reactive oxygen species (ROS), reactive nitrogen species (RNS), and to form bonds between free thiols in amino acids like cysteine, and peptides like glutathione to make disulfides like cystine and the disulfide form of glutathione (GSSG). The rising tide of intracellular oxygen also oxidizes ironsulfur clusters and redox-responsive sites in many proteins, inactivating proteins for macromolecular synthesis and activating proteins that shield the cell membrane from further attack. These include lipoxygenases and NFKB(Serezani et al., 2011), NADPH Oxidases (NOXs)(Jiang et al., 2011), redox-sensitive signaling systems in innate immunity like the purinergic receptors(Hillmann et al., 2009), and transcriptional regulators like Keap1/NRF2, and Sirtuin-FOXO(Speciale et al., 2011). The net result of oxidative shielding in innate immunity is to limit the replication and to prevent the exit of the invading pathogen.

\section{Oxidative Shielding}

Oxidative shielding is a stereotyped response to cellular injury or attack. In order to better understand the fundamental differences between the "oxidative stress" and the "oxidative shielding" perspectives it is helpful to ask and answer a few questions from the viewpoint of these two different schools of thought. This approach is similar to Galileo's dialog(Galileo, 1632 


\section{JPET \#192120 PiP}

(2001)) between adherents of Ptolemaic and Copernican systems as a method of showcasing their relative strengths and weaknesses.

Q1. What triggers the production of superoxide, hydrogen peroxide, and other reactive oxygen species (ROS)?

A1. Hostile, damaging, or unhealthy conditions surrounding the cell. [Both "stress" and "shielding" schools agree with this answer.]

\section{Q2. Where do the ROS come from?}

A2. From mitochondria and specialized enzyme systems in the cell. [Both "stress" and "shielding" schools agree with this answer.]

\section{Q3. What is the function or purpose of ROS?}

A3-The Shielding School: The function of ROS is first, to protect the cell if possible-both as signaling molecules, and by physically decreasing the cellular uptake, release, and exchange of potentially toxic pathogens or chemicals from and with the environment. Second, to actively kill the cell by apoptosis or necrosis when the local environmental conditions threaten to spread to neighboring cells and jeopardize the survival of host. ROS are an effect of disease, not the prime cause. In the shielding school, the organism is considered the ultimate unit of Darwinian selection. The fitness of an individual, in terms of its ability to reproduce, can be substantially increased by rapidly cutting off resources, walling off, or actively killing, damaged or infected cells in a part of the body in order to save the whole.

A3-The Stress School: The function of ROS is to cause cell damage and disease.

Q4. What is the target of effective therapy in diseases associated with increased ROS and ROS-related damage?

A4-The Shielding School: Since the prime cause of disease can ultimately be traced back to toxic exposure, microbial pathogen, unhealthy nutritional practices, nutrient loading, or unhealthy patterns of exercise and activity, therapy should be directed at eliminating these 
causal factors. ROS production will naturally fall back to normal levels when physiologic balance is restored.

A4-The Stress School: Since ROS are the prime cause of disease, therapy should be directed at eliminating or normalizing ROS and ROS-related cell damage.

I leave it to the reader to weigh the strengths and weaknesses of two schools illustrated above.

\section{Randomized Clinical Trials}

The scientific literature is rife with cell culture and animal experiments showing apparent benefits of antioxidant therapy, and opinion papers that advocate antioxidants for treating everything from diabetes to cancer and Alzheimer disease. However, the gold standard of proof in medicine is the randomized clinical trial (RCT). When antioxidants are put to the test in RCTs they generally fail, or worse, show evidence of unexpected harm. For example, in a metaanalysis of 9 clinical trials that evaluated the benefit of treating type 2 diabetes (T2D) with antioxidants such as $\alpha$-tocopherol (Vitamin E), there was no benefit (Suksomboon et al., 2011). Like many purified antioxidant vitamins, Vitamin E is a two-edged sword. The reasons for this are not entirely clear, but may relate to the fact that therapeutic dosing of purified micronutrients and antioxidants intervenes in regulatory pathways that are the symptoms, and not the cause of disease. Vitamin E supplementation, alone or in combination with $\beta$-carotene was shown to increase the risk of lung cancer in smokers(1994). Vitamin C supplementation was found to double the risk of cancer death in non-obese women ( $\mathrm{RR}=2.0 ; 95 \% \mathrm{Cl}=1.12-3.58)$, while having no effect in obese women(Lin et al., 2009). The SELECT clinical trial of vitamin E and selenium was terminated early because of an apparent increase in the risk of new onset diabetes in the selenium group and a 1.6-fold increased risk in prostate cancer in the vitamin $\mathrm{E}$ group(Lippman et al., 2009; Klein et al., 2011). If ROS are at the heart of cancer, diabetes, and heart disease, why are antioxidants so ineffective at preventing or treating these diseases?

Other data that may prove helpful in weighing the merits of the two schools of "oxidative shielding" versus "oxidative stress" are the results of clinical trials in which a therapy 
recommended by the "shielding school", for example diet and exercise (which is known to stimulate ROS(Niess and Simon, 2007)), is directly compared to conventional medical intervention. When this is done in type 2 diabetes and its prodromal metabolic syndrome, diet and exercise are categorically superior to the best drug intervention. A recent meta-analysis of 13 clinical trials involving 3907 subjects found that the odds ratio for disease improvement with diet and exercise was $3.8(95 \% \mathrm{Cl}=2.5-5.9)$, but the odds ratios for disease improvement with drug treatment was $1.6(95 \% \mathrm{Cl}=1.0-2.5)$ (Dunkley et al., 2012). Diet and exercise can actually cure early T2D while simultaneously reducing the risk of heart disease. In contrast, common drug interventions like the thiazolidinedione insulin sensitizing drug rosiglitazone will decrease diabetes, but increases the risk of heart failure(Dagenais et al., 2008).

\section{Evolutionary Conservation of the Oxidative Shielding Response}

The stereotyped oxidative shielding response to danger and metabolic mismatch can be identified in all aerobic forms of life on Earth. Even bacteria have it. For example, E. coli rapidly generates superoxide and hydrogen peroxide in a manner reminiscent of mitochondria-by partially reducing oxygen at the site of $\mathrm{NADH}$ dehydrogenases and quinone acceptor sites along the inner membrane(Cabiscol et al., 2000). The magnitude of the response is regulated by nutrient availability, environmental toxin and infection exposure(Gonzalez-Flecha and Demple, 1997). Interestingly, ROS production by bacteria is highest under conditions of nutrient loading, similar to increased ROS production under nutrient loading in diabetes. Inhibitors of NADH dehydrogenase activity like the pesticides paraquat or rotenone produce a rapid increase in ROS and in mutation rates in the stressed bacteria(Cabiscol et al., 2000). Antioxidant defenses in aerobic bacteria are coordinately upregulated by endogenously produced ROS by redoxreactive thiols on cysteines of peroxide-responsive OxyR, and superoxide-sensitive SoxR transcription factors. 


\section{JPET \#192120 PiP}

Plant cell ROS production leads to cross-linking of tyrosine-rich proteins in the cell wall(Bradley et al., 1992). Animal cells use many mechanisms including the use of another tyrosine-rich protein, melanin, and the production of collagen scar tissue to wall off the chronically disturbed or injured collection of cells. The initiating rise in intracellular oxygen that is caused by the failure of mitochondria to reduce oxygen to water is the hallmark of a metabolic "fever" or mismatch.

Why is it important to make the distinction between oxidative shielding and oxidative damage? When an oxidative shielding response is beneficial to the cell or the organism, then anti-oxidant treatments designed to block or reverse it will have two effects: 1) there will be no effect on the primary cause of the cellular toxicity, eg, the viral infection, toxic exposure, or metabolic mismatch causing the cellular oxidative response, and 2) chronic treatment may ultimately prove harmful because it inhibits the highly evolved protective and hormetic functions of proteincatalyzed oxidative shielding.

\section{Apoptosis, Cellular Altruism, and the Seductive Clarity of Cell Culture}

Cell culture experiments have proven highly successful over the years in answering genetic questions. However, cell culture experiments have not been as reliable, and are often misleading, in answering metabolic questions when the experiment is aimed at answering a question about multicellular development, organ function, or a whole animal phenotype. This happens because of 4 major differences between the metabolic conditions of cell culture and tissues. These can be briefly stated as the Apoptosis, Hyperoxia, Cycling Cell NADPH, and Multicellularity problems.

\section{Apoptosis-Bad for Cells in Culture, Good for the Species}

Mitochondria are the principle regulators of apoptosis(Karbowski, 2010). This process lies at the heart of the developmental program of plants and animals that permits embryos to grow and removes cells that are no longer needed. Another essential function of apoptosis is the physical 
containment of injury or infection. Cells that become infected by viruses, or other microbial pathogens, initiate the program of apoptotic cell death to prevent the spread of infection. Many viruses and other microbes devote substantial genetic resources to thwart the infected cell's effort to commit suicide(Galluzzi et al., 2008). Evolution has preserved and refined the apoptotic program because it confers an increased fitness to the plant or animal during development and under attack. This can be seen as a form of cellular altruism without intent, in which the death and removal of a few infected, injured, or obsolete cells increases the likelihood of survival of the organism. Protein-catalyzed ROS production and membrane and protein oxidation events precede the commitment to apoptosis in most cell types. These genetic and metabolic pathways have been selected over evolutionary time to increase the fitness of the organism. Ultimately the oxidative shielding response confers evolutionary advantage for the organism. This advantage cannot be seen in cell culture because the death of cells in culture occurs without reference to the survival of the whole organism.

\section{Hyperoxia-The Uniquely Oxidizing Environment of the Culture Dish}

Cells in culture are typically grown under ambient oxygen tensions of about 100 Torr that result from diffusion from a $21 \%$ oxygen atmosphere at sea level. They are not usually grown at the $2-4 \%$ oxygen (15-30 Torr) that is normal in tissues. Because all the proteins involved in antioxidant defense evolved under physiologic conditions of 15-30 Torr oxygen, they typically have Kms for oxygen in the 15-30 Torr range. Cell culture hyperoxia in the 30-100 Torr range, will naturally activate antioxidant and pro-oxidant proteins that would otherwise be quiescent and substrate-limited. This makes the interpretation of oxidative changes in cell culture seductively clear. The measurement of a myriad of reactive oxygen species like superoxide and hydrogen peroxide and biomarkers of oxidation like lipid peroxidation is technically simple in cultured cells. However, the judgment that these changes are deleterious in the context of the whole organism is biologically unsound. 


\section{JPET \#192120 PiP}

\section{NADPH-The Electron Carrier for Biomass Synthesis, Not for Cell Work}

Cycling cells have higher NADPH/NADP+ ratios than post-mitotic cells(Attene-Ramos et al., 2005). Cultured cells must double their biomass each day in preparation for division. Postmitotic cells in tissues do not. Post-mitotic cells direct electrons to NADH for cellular work, not NADPH for biomass production. This essential difference between growing and non-growing cells must be grasped before the different roles of mitochondria in growing and non-growing cells can be understood. The synthesis of lipids, proteins, DNA, and RNA requires the use of electrons carried by NADPH to make new carbon-carbon and other chemical bonds. NADPH is made in large amounts by the pentose phosphate pathway (PPP) in which glucose-6-phosphate is used before entering glycolysis to make ribose for DNA and RNA synthesis, and NADPH for macromolecular synthesis and glutathione metabolism(Wamelink et al., 2008). When incoming electrons from glucose and other nutrients are directed to NADPH, those electrons are not available for $\mathrm{NADH}$ used in mitochondrial oxidative phosphorylation. The combined effect of increased NADPH and hyperoxia $\left(21 \% \mathrm{O}_{2}\right)$ in cell culture conspire to amplify superoxide and hydrogen peroxide production by NADPH oxidases, making the study of more subtle factors like regulation of the pentose phosphate pathway by nitric oxide(Bolanos et al., 2008), and compartmental redox regulation during differentiation challenging or impossible.

\section{Multicellularity and Metabolic Complementarity-The Autonomy of Cells in Culture}

In cell culture, investigators necessarily remove the normal connectedness of cells in tissues. As a consequence, single cells in culture must be cell-autonomous, that is, they must synthesize everything they need for growth without reliance on supplies from other cells. This is not the case in somatic tissues. In tissues, distant and neighboring cells adopt complementary metabolic functions. It is wasteful for photoreceptor cells in the eye, for example, to express genes that are used to produce muscle contraction in the heart. Likewise, it is wasteful and potentially toxic for all somatic cells to make a particular hormone like insulin or testosterone. In another example, the cells of the liver lobule clearly differentiate along the gradient of oxygen 
established between the high oxygen present in the vicinity of the hepatic artery in the portal triads where ornithine transcarbamoylase (OTC) is expressed, to the low oxygen present in center of the lobule surrounding the portal vein where ornithine aminotransferase (OAT) is expressed(Naviaux and McGowan, 2000). Somatic cells epigenetically silence unused genes by DNA methylation and other processes. The process of DNA methylation is regulated by folate, B12, and S-adenosylmethionine metabolism (SAM), which are also controlled by mitochondria(Naviaux, 2008). The natural metabolic cooperativity among differentiated cells in the body is lost in cell culture. No longer is there any selective pressure for cells to cooperate as they do in tissues and organs. No longer can the death of a few cells be clearly identified in the context of its evolutionary function to decrease the probability of death of the organism under stress. It is easy to see how an investigator studying cells in a dish might think that active cell processes that cause cell death, like apoptosis and necrosis, are "bad". However, it is the pathways oxidative shielding, and occasionally cell death, that permit the organism to live on and reproduce under the ever-changing conditions of life on Earth.

Tug at a single thread in Nature and you will find it connected to the rest of the Universe.

RK Naviaux (2012)

Modified from John Muir (1911)(Nadler et al., 2004)

\section{Cell Metabolism is like an Ecosystem}

The chemical reactions of the cell take place in a myriad of discrete locations and compartments within the cell that are maintained in thermodynamic disequilibrium. Natural redox boundaries and oxygen gradients are maintained by proteins and membranes in each of these compartments. Cell metabolism can be visualized intuitively as a coral reef ecosystem. The metabolic products of one compartment in the cell are used as resources by other compartments, just as one species of coral can provide resources for another species in the reef. Metabolism is a complex trophic web that stabilizes or destabilizes the differentiated function of the cell. Ultimately, the end products of metabolism are released from the cell into 
the blood and excreted in the urine, back into the external ecosystem. In both the coral reef, and in the microcosm of the cell, small molecule metabolites and signaling molecules drive changes in gene expression, not the reverse. The success of transgenic and gene knock out experiments over the past 20 years has given scientists the impression that genes drive the evolution of metabolism. This is wrong. Rather, it is environmental nutrients and the small molecules of metabolism that drive the evolution of genes.

Over evolutionary time, genes and gene expression patterns evolved to handle the resources provided by the environment. Over shorter time periods of minutes to hours, and weeks to months, nutrients like glucose, fats, and amino acids, and small molecules of metabolism are the forcing variables that induce the changes in enzyme activity and gene expression associated with feeding, fasting, and seasonal variations in nutrient availability. The amino acid leucine plays a central role in stimulating the master fuel regulator mTOR, and inhibiting AMP Kinase, and autophagy(Han et al., 2012).

Many intermediary metabolites act differently inside and outside the cell. Inside the cell they act as carbon skeletons for fat, protein, carbohydrate, DNA and RNA synthesis. Outside the cell they act as signaling molecules that bind cell receptors and alter gene expression. For example, ATP is an energy-carrying molecule inside the cell. Outside the cell, ATP is a "mitokine" and damage-associated molecular pattern (DAMP)(Zhang et al., 2010) that binds ionotropic and metabotropic purinergic receptors, activating innate immunity and inflammatory pathways(Marques-da-Silva et al., 2011). Succinate is a Krebs cycle intermediate inside the cell, but binds the G-protein coupled receptor 91 (GPR91) on the cell surface that can reverse the anti-platelet activity of aspirin(Spath et al., 2012). In another example, citric acid inside the cell is the namesake of the "citric acid cycle", known more commonly as the Krebs cycle. Outside the cell, citrate is a mobile carbon source and barometer of nutrient availability. Citrate is taken into cells via a cell surface transporter called INDY (for "I'm Not Dead Yet") that when 
mutated leads to cellular citrate depletion and mimics the life-extending effects of caloric restriction(Birkenfeld et al., 2011). These genetic manipulations illustrate the role of small molecule metabolites as being prime regulators of cell gene expression. The literature on this topic of metabolic regulation of gene expression is extensive and the interested reader is referred to a recent review(Buchakjian and Kornbluth, 2010).

\section{Metabolic Consequences of Nutrient Excess}

In 1929, Herbert Crabtree used mouse cancer cells to show that when glucose was added to the medium, oxygen consumption decreased(Crabtree, 1929). Mitochondria were not yet identified as the oxygen-consuming particles. Otto Warburg coined the term the "Atmungsferment", the iron and cytochrome-containing respiratory catalyst, to describe the site of oxygen consumption in cells(Warburg and Negelein, 1928) later discovered to be mitochondria. The Crabtree effect has been called the inverted Pasteur effect, since in the Pasteur effect exposure to oxygen was found to inhibit anaerobic glycolysis. The magnitude of the respiratory inhibition by glucose caused by the Crabtree effect varies between $5-50 \%$ (Ibsen, 1961) depending on the cell type and the concentration of glucose added. The Crabtree effect plays an important role in many conditions, including diabetes, in which persistently high levels of calories and glucose produce a relative decrease in mitochondrial oxygen consumption. There are several biochemical mechanisms that combine to produce the Crabtree effect under conditions of nutrient loading(Sussman et al., 1980). The most significant is the inhibitory effect of the cytosolically-produced $[\mathrm{ATP}] /[\mathrm{ADP}][\mathrm{Pi}]$ ratio on mitochondrial ATP synthesis. This happens because mitochondrial oxidative phosphorylation requires cytosolic $\mathrm{ADP}$ and $\mathrm{Pi}$ to make ATP. When cytosolic ATP rises and ADP falls, ADP becomes limiting in mitochondria, and the excesses of cytosolic ATP inhibits the forward action of mitochondrial ATP synthase (Complex V) by classical mechanisms of product inhibition. This induces a chemiosmotic backpressure of protons in the mitochondrial inner membrane space and hyperpolarizes the mitochondrial membrane, ie makes the $\Delta \Psi \mathrm{m}$ more negative. Excess electrons that enter 


\section{JPET \#192120 PiP}

mitochondria under these conditions cannot be used to make ATP because of the backpressure. The partial reduction of oxygen to superoxide and peroxide serves as a "pressure release valve"(Fisher-Wellman and Neufer, 2012), that permits excess electrons to be dissipated and excess oxygen to be exported from the cell in the form of soluble hydrogen peroxide. All these biophysical and thermodynamic consequences of nutrient loading result in a net decrease in mitochondrial oxygen consumption that we call the Crabtree effect.

Because mitochondria create the oxygen sink for the cell, when mitochondrial extraction of oxygen is decreased, cell and tissue oxygen levels rise, and the tissue extraction of oxygen from the blood falls. This is observed clinically as a decrease in the arteriovenous (A-V) difference in $\mathrm{pO}_{2}$. Physiologically, this is interpreted as "wasted" oxygenation. Ultimately, it results in pruning of capillary beds and reductions in tissue vascularity, ie, peripheral vascular disease. Over time, this leads to chronic tissue hypoxia, ischemia, and loss of organ function, to heart and kidney failure, and chronic neurodegenerative disease.

\section{Tissue Hypoxia and Ocean Hypoxia-Universal Metabolic Response to Nutrient Loading}

There is an ocean-scale analog to the cellular Crabtree effect. When excessive amounts of nutrients are concentrated in agricultural fertilizer runoff and urban waste and carried downriver to the ocean, the metabolism of plankton in the sea is changed. Ultimately this process creates seasonal and persistent "dead zones" of ocean hypoxia(Diaz and Rosenberg, 2008) that cannot support coral, fish, shellfish, or any eukaryotic life larger than a nematode or a few small snails. Repopulating these lost ecosystems can take years of concerted remediation. Excessive "calories" and nutrients injected into the ocean trigger an ecosystem-scale Crabtree effect, in a biphasic process that is similar to Type II Diabetes. First there is an inhibition of aerobic metabolism and a rapid increase in algal and cyanobacterial oxygenic photosynthesis to create plankton blooms. This occurs for the same metabolic reasons as in nutrient-loaded human cells-excess nutrients exceed the oxidative capacity of the cells and redirects these excess 
electrons to NADPH and biomass synthesis. Non-photosynthetic cells also shift to this more fermentative metabolism to facilitate rapid conversion of the new nutrient resources to biomass. In diabetes, this shift to biosynthesis leads to organ hypertrophy and the accumulation of adipose tissue and intracellular fat. The net result in the ocean is a transient increase in water oxygen because of photosynthesis and decreased oxygen utilization by heterotrophs. This metabolic shift is quantified by biological oceanographers as an increase in bacterial growth efficiency (BGE)(Azam and Malfatti, 2007). This first stage of hyperoxia is short-lived and rarely measured. This is similar to the situation in diabetic tissues exposed to excessive nutrients. The second stage of the response to nutrient loading is a decrease in water oxygen. In the ocean this occurs because the excess plankton biomass produced by the blooms dies and becomes fuel for other bacteria that extract oxygen from the water to process the dead biomass. Hypoxia results. In tissues, chronic nutrient excess leads to tissue hypoxia because of capillary pruning that results from decreased mitochondrial oxygen consumption as described above, and from decreased arteriovenous $\mathrm{pO}_{2}$ differences. Initially, the tissue hypoxia from excess nutrient load is patchy, resulting in localized areas of ischemia and segments of dysfunction. Later, the patches of organ hypoxia begin to merge and significant organ dysfunction occurs.

\section{Redox Compartments and Oxygen Gradients in the Cell}

The intracellular "ecosystem" of the eukaryotic cell is comprised of at least 8 different organellar compartments, each with its own redox poise (Fig. 1). These include: lysosomes(Gille and Nohl, 2000), smooth ER, rough ER(Hwang et al., 1992), the Golgi(Navas et al., 2010), the cytosol(Go and Jones, 2008), peroxisomes(Yano et al., 2010), the nucleus(Go and Jones, 2011), and the mitochondrial matrix(Go and Jones, 2008). These compartments are not in equilibrium because the proteins that maintain the redox in each compartment, and the membranes that separate them are not diffusible(Jones, 2010). The standard redox potentials of each of these compartments with regard to the glutathione couple (GSH/GSSG) have been measured (Table 1). 
In contrast to sharp boundaries of redox poise that define the different organelles of the cell, the concentration of oxygen at any point in the cell is determined by oxygen diffusion along its gradient from the capillary to the mitochondrial matrix. With a little imagination, one can imagine that each organelle "swims" to a point in the cellular ecosystem that best meets its need for oxygen and nutrients. The oxygen partial pressure of 40 Torr in venous plasma, 30 Torr in the pericellular space(Pittman, 2011), and 0.02-0.2 Torr (25-250 nM) in mitochondria(Scandurra and Gnaiger, 2010) can be conceptualized in an "oxygen well" or "target diagram" of the cell (Fig. 2A). When the measured glutathione redox couple is plotted against the log of the partial pressure of oxygen in Torr, a linear regression can be calculated. The formula for this line is: GSH/GSSG Redox (in mV) = 82.6* Log(Oxygen in Torr) - 272 (Fig. 2B). This connection between oxygen concentration at every point along the oxygen diffusion gradient, and compartmental redox helps explain the profound effect that small changes in mitochondrial oxygen consumption, leading to increased dissolved oxygen concentrations in throughout the extramitochondrial compartments of the cell, can have on the metabolic and work performance of the cell. Indeed, the cell cycle has been characterized as a redox cycle(Burhans and Heintz, 2009).

\section{Cellular Thermodynamics and Work}

llya Prigogine described the mathematics of dissipative systems in which physical work and the capacity for self-organization can be extracted from the environment by maintaining a compartmentalized, collective chemical "distance" from thermodynamic equilibrium(Prigogine, 1984). Mitochondria set a limit on the maximum free energy available for work by a cell by consuming oxygen and transforming metabolites. Highly aerobic mitochondria produce a deep oxygen gradient (Fig. 3) of nearly 150-fold, from 30 Torr in the pericellular space to 0.2 Torr(Scandurra and Gnaiger, 2010) at the site of cytochrome c oxidase (COX) in the inner mitochondrial membrane. The depth of the oxygen sink creates the potential energy that acts 
like a coiled spring to drive the living clockwork of metabolism, development, differentiation, and organ function.

Less active mitochondria maintain more shallow oxygen gradients and have a lower work capacity, but greater proliferative capacity. This is illustrated in Fig. 3 on the left. This occurs because electrons in the cytosol are redirected to NADPH and macromolecular synthesis, and away from usage as NADH in mitochondria when oxygen consumption rates are lower (Fig. 3). The ultimate energy currency of the cell is electrons that enter the cell in the form of the chemical bonds in the carbon skeletons of nutrients like glucose, amino acids, and fatty acids. Mitochondrial oxygen consumption determines the depth of the oxygen sink and ultimately tips the redox balance of the cell either toward growth and proliferation, or to differentiation and work.

\section{Metabolic Memory and Exercise}

Short-duration physical or chemical stimuli produce long-term cellular effects by inducing kinetically-linked chains of events that can be measured metabolically and by protein changes. This phenomenon is called metabolic memory. It is the result of post-translational activation and inhibition, and transcriptional activation and inhibition events that are initiated by the shortduration stimulus. Many examples are known. The most widely reported example is the longterm effect of short-term, strict metabolic management in patients with diabetes. Even after the management of diabetes is relaxed, long-term metabolic changes in insulin sensitivity and decreased incidence of vascular complications and end-organ disease are observed(Cooper, 2009).

Physical exercise is perhaps the best-known method of inducing metabolic memory. Even a single session of exercise will produce an increase in basal metabolic rate for hours after the session(LaForgia et al., 2006). Adaptive strength and cardiovascular benefits can be measured over days. Regular resistance training produces metabolic memory and reverses age-related 
changes in skeletal muscle over months(LaForgia et al., 2006). The mechanisms of these adaptive changes to exercise appear to require the transient pulses of reactive oxygen species (ROS) that are produced(Niess and Simon, 2007).

\section{Antioxidant Therapy Inhibits the Benefits of Exercise}

What happens if the normal amounts of superoxide and hydrogen peroxide produced during exercise are inhibited by treatment with antioxidants? In a ground-breaking study in 2009, Ristow and his colleagues studied the effect of antioxidant supplements (Vitamin C 1000 mg/day; Vitamin E 400 IU/day) on insulin sensitivity and markers like plasma adiponectin and the master mitochondrial biogenesis regulator PGC1 $\alpha$ after one month of exercise(Ristow et al., 2009). They found that the subjects who exercised and did not take antioxidant supplements had significant improvements in insulin sensitivity, adiponectin, and PGC1 $\alpha$. Antioxidants inhibited these metabolic benefits of exercise. The authors proposed that mitochondrial hormesis, or beneficial adaptation to stress, requires transient oxidative stress to induce the downstream changes in nuclear gene expression that promote health and longevity(Ristow and Schmeisser, 2011).

\section{Antioxidant Treatment Decreases Tissue Perfusion}

Experimental work has also been conducted to study the effects of vitamin $C$ and the antioxidant tempol on skeletal muscle performance. When antioxidants were provided acutely, Copp, et al. showed that spinotrapezius muscle contractile force was decreased $25 \%$ (Copp et al., 2009). Muscle blood flow was also reduced, and the resting oxygen tension in the skeletal muscle was reduced 14\%, from 29.9 Torr to 25.6 Torr(Copp et al., 2009). The authors report that optimum blood flow and optimum contractile force depend on the redox state of skeletal muscle. Therefore, antioxidant therapy resulted in decreased muscle perfusion and contractile performance measured acutely(Copp et al., 2009), and interfered with beneficial effects of exercise such as increased insulin sensitivity when measured after one month of supplementation(Ristow and Schmeisser, 2011). 


\section{JPET \#192120 PiP}

\section{Phytonutrients and Xenohormesis}

Plants and animals that share an ecosystem coevolve. Many plants depend on mammals and birds for seed dispersal. Therefore, the survival of these plants is dependent on the survival of the mammals and birds that facilitate the dispersal of their seeds. If the coevolving animals do not survive a drought or other seasonal hardship, the plants also perish. Plants have developed secondary metabolites and small molecule stress hormones like resveratrol that not only help the plant survive, but also activate molecules like the Sirtuins in animal cells that produce a metabolic shift that improves drought and heat tolerance in the animals. Resveratrol is a polyphenol that activates the lysine-deacetylase activity of SIRT1 under conditions of caloric restriction that promote a high $\mathrm{NAD}+\mathrm{NADH}$ ratio. The principle health benefits of fruits and vegetables lie not just in the vitamins, minerals, and fiber they provide, but in the dozens to hundreds of phytonutrients like the polyphenols, flavonoids, terpenoids, and quinones that have evolved to activate mammalian cellular targets like sirtuins, cytoskeleton, tyrosine protein kinases, PI3 Kinase, MAP kinases, and transcription factors like Keap1 and NRF2(Murakami and Ohnishi, 2012). Animals that consume foliage from stressed plants redirect energy resources away from reproductive pathways. This results in a decrease in fecundity. However, the animals benefit directly from an increase in their own heat and drought tolerance. This phenomenon in which coevolving plants produce signaling molecules that benefit ecologicallyconnected animals is called "xenohormesis"(Howitz and Sinclair, 2008).

An important fact has emerged in the study of the antioxidant properties of plants. Just as in the response to exercise, the durable antioxidant effects of botanicals occur because of their acute, but transient, pro-oxidant (electrophilic and/or ROS-generating) effects(Speciale et al., 2011). Electrophiles abstract electrons from (oxidize) other molecules. Metabolically, this is similar to the action of intracellular microbial pathogens that "steal" electrons to make carbon-carbon bonds and replicate the parasite biomass at the expense of the cell. For this reason, the 
stereotyped metabolic responses antioxidant defenses and innate immunity are activated similarly by electrophiles and certain microbial pathogens. Potent phytonutrients like curcurmin in turmeric, quercetin in onions, sulforaphane in broccoli, and epigallocatechingallate (EGCG) in green tea produce their antioxidant effects by acting acutely as pro-oxidants in the cell, and inducing metabolic hormesis. The electrophilic chemical nature of these compounds upregulates Keap1/NRF2-mediated transcription of dozens of antioxidant defense genes that contain Antioxidant Response Elements (AREs; or Electrophile-Response Elements, EpREs). These include enzymes for glutathione synthesis and metabolism $(\gamma$-glutamylcysteine synthetase, glutathione peroxidase, glutathione reductase, sulforedoxin, and thioredoxin), stress proteins like heme oxygenase-1, and drug detoxification enzymes like glutathione S-transferase, and NADPH-quinone oxidoreductase, and cytokines like IL6(Speciale et al., 2011).

\section{Conclusions}

ROS and oxidative changes in chronic disease are the symptoms of disease and not the cause. Indeed, transient and regular stimulation of ROS production is required for mitochondrial hormesis and the beneficial physiologic adaptations associated with exercise and a diet rich in fruits and vegetables. Membrane lipid peroxidation, fibrosis, protein oxidation, and hundreds of other markers that were formerly cataloged as "oxidative damage" need to be understood as cellular "oxidative shielding". The conserved pathways of oxidative shielding are proteincatalyzed reactions that evolved as the first steps in innate immunity. They evolved to protect the cell from chemical and microbial threats in the environment. Both oxidative and reductive stress will trigger cellular oxidative shielding. Oxidative shielding takes many forms in different bacterial, plant, and animal phyla. All forms ultimately increase membrane rigidity, decrease membrane permeability, and inhibit cell division. System-wide conditions like calorie restriction or nutrient loading modify the cellular response to stress. When stress coincides with dietary nutrient excess, cellular electrons are transferred preferentially to NADPH and not NADH, 
glycolytically-synthesized ATP inhibits mitochondrial oxygen consumption via the Crabtree effect, and chronic inflammation results.

Research efforts need to be redirected. Catalogs of the many forms of oxidative changes that are found in a hundred chronic diseases provide no insight into the underlying pathogenesis of disease. Treatment of oxidative changes in chronic disease with antioxidants is similar to treating a fever with aspirin instead of treating the pneumonia. If the clinical outcome selected for monitoring the disease is the fever, then aspirin will be "clinically proven" to be effective at improving the "disease". However, the untreated pneumonia might still kill the patient. Better to "treat" the fever by treating the bacterial cause of the pneumonia. Certain antioxidants might be shown to decrease oxidative markers like nitro-tyrosine. However, nitro-tyrosine modified proteins are a symptom, not the disease. More patients will benefit when the true cause of the fever-the cause of the disease-is identified and treated.

New methods of targeted and untargeted metabolomics will help decode the language of metabolism in disease(Tautenhahn et al., 2011; Yanes et al., 2011) and assist physicians in providing personalized medical treatment. NextGen treatments will need to restore the normal "ecology" of metabolism. Complex diseases like autism, autoimmune disease, diabetes, cancer, kidney and cardiovascular disease do not have simple causes that are true for every patient. Personalized causes must be sought and new diagnostic tools developed. Identification of the causal chemistry and environmental factors that trigger innate immunity and metabolic memory that initiate and sustain oxidative shielding will lead to fresh new therapies for old diseases.

AUTHOR CONTRIBUTIONS: RKN is the sole author of this work. 


\section{JPET \#192120 PiP}

\section{REFERENCES}

(1994) The effect of vitamin E and beta carotene on the incidence of lung cancer and other cancers in male smokers. The Alpha-Tocopherol, Beta Carotene Cancer Prevention Study Group. The New England journal of medicine 330:1029-1035.

Attene-Ramos MS, Kitiphongspattana K, Ishii-Schrade K and Gaskins HR (2005) Temporal changes of multiple redox couples from proliferation to growth arrest in IEC-6 intestinal epithelial cells. Am J Physiol Cell Physiol 289:C1220-1228.

Azam F and Malfatti F (2007) Microbial structuring of marine ecosystems. Nat Rev Microbiol 5:782-791.

Birkenfeld AL, Lee HY, Guebre-Egziabher F, Alves TC, Jurczak MJ, Jornayvaz FR, Zhang D, Hsiao JJ, Martin-Montalvo A, Fischer-Rosinsky A, Spranger J, Pfeiffer AF, Jordan J, Fromm MF, Konig J, Lieske S, Carmean CM, Frederick DW, Weismann D, Knauf F, Irusta PM, De Cabo R, Helfand SL, Samuel VT and Shulman GI (2011) Deletion of the mammalian INDY homolog mimics aspects of dietary restriction and protects against adiposity and insulin resistance in mice. Cell metabolism 14:184-195.

Bolanos JP, Delgado-Esteban M, Herrero-Mendez A, Fernandez-Fernandez S and Almeida A (2008) Regulation of glycolysis and pentose-phosphate pathway by nitric oxide: impact on neuronal survival. Biochim Biophys Acta 1777:789-793.

Bradley DJ, Kjellbom P and Lamb CJ (1992) Elicitor- and wound-induced oxidative cross-linking of a proline-rich plant cell wall protein: a novel, rapid defense response. Cell 70:21-30.

Brinkmann $\mathrm{H}$ and Philippe $\mathrm{H}$ (2007) The diversity of eukaryotes and the root of the eukaryotic tree. Advances in experimental medicine and biology 607:20-37.

Buchakjian MR and Kornbluth S (2010) The engine driving the ship: metabolic steering of cell proliferation and death. Nat Rev Mol Cell Biol 11:715-727.

Burhans WC and Heintz NH (2009) The cell cycle is a redox cycle: linking phase-specific targets to cell fate. Free radical biology \& medicine 47:1282-1293. 


\section{JPET \#192120 PiP}

Cabiscol E, Piulats E, Echave P, Herrero E and Ros J (2000) Oxidative stress promotes specific protein damage in Saccharomyces cerevisiae. The Journal of biological chemistry 275:27393-27398.

Cooper ME (2009) Metabolic memory: implications for diabetic vascular complications. Pediatr Diabetes 10:343-346.

Copp SW, Ferreira LF, Herspring KF, Hirai DM, Snyder BS, Poole DC and Musch TI (2009) The effects of antioxidants on microvascular oxygenation and blood flow in skeletal muscle of young rats. Exp Physiol 94:961-971.

Crabtree HG (1929) Observations on the carbohydrate metabolism of tumours. Biochem J 23:536-545.

Dagenais GR, Gerstein HC, Holman R, Budaj A, Escalante A, Hedner T, Keltai M, Lonn E, McFarlane S, McQueen M, Teo K, Sheridan P, Bosch J, Pogue J and Yusuf S (2008) Effects of ramipril and rosiglitazone on cardiovascular and renal outcomes in people with impaired glucose tolerance or impaired fasting glucose: results of the Diabetes REduction Assessment with ramipril and rosiglitazone Medication (DREAM) trial. Diabetes care 31:1007-1014.

Diaz RJ and Rosenberg R (2008) Spreading dead zones and consequences for marine ecosystems. Science 321:926-929.

Dobzhansky T (1973) Nothing in biology makes sense except in the light of evolution. American Biology Teacher 35:125-129.

Dunkley AJ, Charles K, Gray LJ, Camosso-Stefinovic J, Davies MJ and Khunti K (2012) Effectiveness of interventions for reducing diabetes and cardiovascular disease risk in people with metabolic syndrome: systematic review and mixed treatment comparison meta-analysis. Diabetes, obesity \& metabolism.

Fisher-Wellman KH and Neufer PD (2012) Linking mitochondrial bioenergetics to insulin resistance via redox biology. Trends in endocrinology and metabolism: TEM 23:142-153. 
Galileo G (1632 (2001)) Dialogue Concerning the Two Chief World Systems: Ptolemaic and Copernican (English translation of the original Italian). Modern Library.

Galluzzi L, Brenner C, Morselli E, Touat Z and Kroemer G (2008) Viral control of mitochondrial apoptosis. PLoS Pathog 4:e1000018.

Gille L and Nohl H (2000) The existence of a lysosomal redox chain and the role of ubiquinone. Archives of biochemistry and biophysics 375:347-354.

Gnaiger E, Steinlechner-Maran R, Mendez G, Eberl T and Margreiter R (1995) Control of mitochondrial and cellular respiration by oxygen. Journal of bioenergetics and biomembranes 27:583-596.

Go YM and Jones DP (2008) Redox compartmentalization in eukaryotic cells. Biochim Biophys Acta 1780:1273-1290.

Go YM and Jones DP (2011) Cysteine/cystine redox signaling in cardiovascular disease. Free radical biology \& medicine 50:495-509.

Gonzalez-Flecha B and Demple B (1997) Transcriptional regulation of the Escherichia coli oxyR gene as a function of cell growth. Journal of bacteriology 179:6181-6186.

Han JM, Jeong SJ, Park MC, Kim G, Kwon NH, Kim HK, Ha SH, Ryu SH and Kim S (2012) Leucyl-tRNA Synthetase Is an Intracellular Leucine Sensor for the mTORC1-Signaling Pathway. Cell 149:410-424.

Harman D (1956) Aging: A theory based on free radical and radiation chemistry. $J$ Gerontol 11:298-300.

Hillmann P, Ko GY, Spinrath A, Raulf A, von Kugelgen I, Wolff SC, Nicholas RA, Kostenis E, Holtje HD and Muller CE (2009) Key determinants of nucleotide-activated G proteincoupled P2Y(2) receptor function revealed by chemical and pharmacological experiments, mutagenesis and homology modeling. Journal of medicinal chemistry 52:2762-2775.

Hohmann-Marriott MF and Blankenship RE (2011) Evolution of photosynthesis. Annu Rev Plant Biol 62:515-548. 


\section{JPET \#192120 PiP}

Holland HD (2006) The oxygenation of the atmosphere and oceans. Philos Trans $R$ Soc Lond $B$ Biol Sci 361:903-915.

Howitz KT and Sinclair DA (2008) Xenohormesis: sensing the chemical cues of other species. Cell 133:387-391.

Hwang C, Sinskey AJ and Lodish HF (1992) Oxidized redox state of glutathione in the endoplasmic reticulum. Science 257:1496-1502.

Ibsen KH (1961) The Crabtree effect: a review. Cancer research 21:829-841.

Jiang F, Zhang Y and Dusting GJ (2011) NADPH oxidase-mediated redox signaling: roles in cellular stress response, stress tolerance, and tissue repair. Pharmacol Rev 63:218-242.

Jones DP (2010) Redox sensing: orthogonal control in cell cycle and apoptosis signalling. Journal of internal medicine 268:432-448.

Karbowski M (2010) Mitochondria on guard: role of mitochondrial fusion and fission in the regulation of apoptosis. Advances in experimental medicine and biology 687:131-142.

Klein EA, Thompson IM, Jr., Tangen CM, Crowley JJ, Lucia MS, Goodman PJ, Minasian LM, Ford LG, Parnes HL, Gaziano JM, Karp DD, Lieber MM, Walther PJ, Klotz L, Parsons JK, Chin JL, Darke AK, Lippman SM, Goodman GE, Meyskens FL, Jr. and Baker LH (2011) Vitamin $\mathrm{E}$ and the risk of prostate cancer: the Selenium and Vitamin E Cancer Prevention Trial (SELECT). JAMA : the journal of the American Medical Association 306:1549-1556.

Knoll AH, Javaux EJ, Hewitt D and Cohen P (2006) Eukaryotic organisms in Proterozoic oceans. Philos Trans R Soc Lond B Biol Sci 361:1023-1038.

LaForgia J, Withers RT and Gore CJ (2006) Effects of exercise intensity and duration on the excess post-exercise oxygen consumption. J Sports Sci 24:1247-1264.

Lin J, Cook NR, Albert C, Zaharris E, Gaziano JM, Van Denburgh M, Buring JE and Manson JE (2009) Vitamins $C$ and $E$ and beta carotene supplementation and cancer risk: a randomized controlled trial. Journal of the National Cancer Institute 101:14-23. 
Lippman SM, Klein EA, Goodman PJ, Lucia MS, Thompson IM, Ford LG, Parnes HL, Minasian LM, Gaziano JM, Hartline JA, Parsons JK, Bearden JD, 3rd, Crawford ED, Goodman GE, Claudio J, Winquist E, Cook ED, Karp DD, Walther P, Lieber MM, Kristal AR, Darke AK, Arnold KB, Ganz PA, Santella RM, Albanes D, Taylor PR, Probstfield JL, Jagpal TJ, Crowley JJ, Meyskens FL, Jr., Baker LH and Coltman CA, Jr. (2009) Effect of selenium and vitamin $\mathrm{E}$ on risk of prostate cancer and other cancers: the Selenium and Vitamin $\mathrm{E}$ Cancer Prevention Trial (SELECT). JAMA : the journal of the American Medical Association 301:39-51.

Marques-da-Silva C, Burnstock G, Ojcius DM and Coutinho-Silva R (2011) Purinergic receptor agonists modulate phagocytosis and clearance of apoptotic cells in macrophages. Immunobiology 216:1-11.

Murakami A and Ohnishi K (2012) Target molecules of food phytochemicals: Food science bound for the next dimension. Food \& function 3:462-476.

Nadler JJ, Moy SS, Dold G, Trang D, Simmons N, Perez A, Young NB, Barbaro RP, Piven J, Magnuson TR and Crawley JN (2004) Automated apparatus for quantitation of social approach behaviors in mice. Genes Brain Behav 3:303-314.

Navas P, Sun I, Crane FL, Morre DM and Morre DJ (2010) Monoascorbate free radicaldependent oxidation-reduction reactions of liver Golgi apparatus membranes. Journal of bioenergetics and biomembranes 42:181-187.

Naviaux RK (2008) Mitochondrial control of epigenetics. Cancer Biol Ther 7:1191-1193.

Naviaux RK and McGowan KA (2000) Organismal effects of mitochondrial dysfunction. Hum Reprod 15 Suppl 2:44-56.

Niess AM and Simon P (2007) Response and adaptation of skeletal muscle to exercise--the role of reactive oxygen species. Front Biosci 12:4826-4838.

Pagliarini DJ, Calvo SE, Chang B, Sheth SA, Vafai SB, Ong SE, Walford GA, Sugiana C, Boneh A, Chen WK, Hill DE, Vidal M, Evans JG, Thorburn DR, Carr SA and Mootha VK (2008) 
A mitochondrial protein compendium elucidates complex I disease biology. Cell 134:112123.

Pittman RN (2011) Oxygen gradients in the microcirculation. Acta Physiol (Oxf) 202:311-322.

Prigogine I (1984) Order Out of Chaos. Bantam.

Rasmussen B, Fletcher IR, Brocks JJ and Kilburn MR (2008) Reassessing the first appearance of eukaryotes and cyanobacteria. Nature 455:1101-1104.

Ristow M and Schmeisser S (2011) Extending life span by increasing oxidative stress. Free radical biology \& medicine 51:327-336.

Ristow M, Zarse K, Oberbach A, Kloting N, Birringer M, Kiehntopf M, Stumvoll M, Kahn CR and Bluher M (2009) Antioxidants prevent health-promoting effects of physical exercise in humans. Proceedings of the National Academy of Sciences of the United States of America 106:8665-8670.

Rolfsson O, Palsson BO and Thiele I (2011) The human metabolic reconstruction Recon 1 directs hypotheses of novel human metabolic functions. BMC systems biology 5:155.

Scandurra FM and Gnaiger E (2010) Cell respiration under hypoxia: facts and artefacts in mitochondrial oxygen kinetics. Advances in experimental medicine and biology 662:7-25.

Schellenberger J, Park JO, Conrad TM and Palsson BO (2010) BiGG: a Biochemical Genetic and Genomic knowledgebase of large scale metabolic reconstructions. BMC bioinformatics 11:213.

Serezani CH, Lewis C, Jancar S and Peters-Golden M (2011) Leukotriene B4 amplifies NFkappaB activation in mouse macrophages by reducing SOCS1 inhibition of MyD88 expression. The Journal of clinical investigation 121:671-682.

Shepherd D and Garland PB (1969) The kinetic properties of citrate synthase from rat liver mitochondria. Biochem J 114:597-610.

Spath B, Hansen A, Bokemeyer C and Langer F (2012) Succinate reverses in-vitro platelet inhibition by acetylsalicylic acid and P2Y receptor antagonists. Platelets 23:60-68. 
Speciale A, Chirafisi J, Saija A and Cimino F (2011) Nutritional antioxidants and adaptive cell responses: an update. Current molecular medicine 11:770-789.

Suksomboon N, Poolsup N and Sinprasert S (2011) Effects of vitamin E supplementation on glycaemic control in type 2 diabetes: systematic review of randomized controlled trials. Journal of clinical pharmacy and therapeutics 36:53-63.

Sussman I, Erecinska M and Wilson DF (1980) Regulation of cellular energy metabolism: the Crabtree effect. Biochim Biophys Acta 591:209-223.

Tang KH and Blankenship RE (2010) Both forward and reverse TCA cycles operate in green sulfur bacteria. The Journal of biological chemistry 285:35848-35854.

Tautenhahn R, Patti GJ, Kalisiak E, Miyamoto T, Schmidt M, Lo FY, McBee J, Baliga NS and Siuzdak G (2011) metaXCMS: second-order analysis of untargeted metabolomics data. Anal Chem 83:696-700.

Wamelink MM, Struys EA and Jakobs C (2008) The biochemistry, metabolism and inherited defects of the pentose phosphate pathway: a review. $J$ Inherit Metab Dis 31:703-717.

Warburg OH and Negelein E (1928) Über den Einfluss der Wellenlänge auf die Verteilung des Atmungsferments. (Absorptionsspektrum des Atmungsferments.) (On the influence of wavelength on the activity of the respiratory ferment [in the presence of carbon monoxide] .). Biochemische Zeitschrift 193:339-346.

West AP, Shadel GS and Ghosh S (2011) Mitochondria in innate immune responses. Nat Rev Immunol 11:389-402.

West JB (2000) Respiratory Physiology: The Essentials. Lippincott.

Wichels A, Biel SS, Gelderblom HR, Brinkhoff T, Muyzer G and Schutt C (1998) Bacteriophage diversity in the North Sea. Appl Environ Microbiol 64:4128-4133.

Winslow RM (2007) The role of hemoglobin oxygen affinity in oxygen transport at high altitude. Respir Physiol Neurobiol 158:121-127.

Yanes O, Tautenhahn R, Patti GJ and Siuzdak G (2011) Expanding coverage of the metabolome for global metabolite profiling. Anal Chem 83:2152-2161. 


\section{JPET \#192120 PiP}

Yang M, Clarke AM and Crawley JN (2009) Postnatal lesion evidence against a primary role for the corpus callosum in mouse sociability. Eur J Neurosci 29:1663-1677.

Yano T, Oku M, Akeyama N, Itoyama A, Yurimoto H, Kuge S, Fujiki Y and Sakai Y (2010) A novel fluorescent sensor protein for visualization of redox states in the cytoplasm and in peroxisomes. Molecular and cellular biology 30:3758-3766.

Zhang Q, Raoof M, Chen Y, Sumi Y, Sursal T, Junger W, Brohi K, Itagaki K and Hauser CJ (2010) Circulating mitochondrial DAMPs cause inflammatory responses to injury. Nature 464:104-107.

\section{FINANCIAL SUPPORT}

RKN thanks the UCSD Christini Fund, the Wright Foundation, the Lennox Foundation, the Jane Botsford-Johnson Foundation, and the Hailey's Wish Foundation for their support. 


\section{FIGURE LEGENDS}

Figure 1. Redox Boundaries and Oxygen Tensions in the Organellar Compartments of the Cell. Values of oxygen concentration, glutathione redox potential, $\mathrm{pH}$, and associated references are listed in Table 1.

Figure 2. Conceptualized Oxygen Well and Redox Diagram of the Cell. A. Oxygen Well Diagram and Redox Zones of the Cell. This is a schematic that illustrates the measured standard redox potential of the glutathione couple (GSH/GSSG) in six compartments of the cell. B. Semilog plot of the partial pressure of oxygen shows a linear correlation with compartmental redox potential. GSH/GSSG Redox (in $\mathrm{mV}$ ) = 82.6* Log(Oxygen in Torr) - 272.

Figure 3. Mitochondria Create the Oxygen Gradient the Generates the Thermodynamic Potential Energy that Drives Metabolism and Cellular Work. Highly active mitochondria illustrated on the right create a deep oxygen sink of 150 -fold (30 Torr to 0.2 Torr) that is highly electrophilic, attracting electrons in the form of $\mathrm{NADH}$ like iron to a magnet. This potential energy is harnessed like a coiled spring to power the functional capacity of the cell and to provide metabolic reserve that be made available under times of stress. Less active mitochondria on the left, produce a shallower gradient of 15 -fold in this example (30 Torr to 2 Torr) and have a lower work capacity, and less oxidative reserve, but are able to divert electrons more efficiently to NADPH for biosynthesis and cell proliferation. 
Table 1. Compartmental Redox and Oxygen Tension in Mammalian Cells.

\begin{tabular}{|c|c|c|c|}
\hline Compartment & pH & $\begin{array}{l}\text { Glutathione Redox } \\
\text { (GSH/GSSG; mV)\# }\end{array}$ & $\begin{array}{l}\text { Dissolved Oxygen } \\
\text { (Torr) }\end{array}$ \\
\hline Mitochondrial Matrix & $7.8-8.0$ & $\begin{array}{c}-330 \\
\text { (Go and Jones, } \\
2008)\end{array}$ & $\begin{array}{c}0.2 \\
\text { (Gnaiger et al., 1995; } \\
\text { Scandurra and } \\
\text { Gnaiger, 2010) }\end{array}$ \\
\hline Nucleus & 7.6 & $\begin{array}{c}-280 \\
\text { (Go and Jones, } \\
\text { 2011) }\end{array}$ & $0.8^{*}$ \\
\hline Peroxisomes & 7.6 & $\begin{array}{c}-270 \\
\text { (Yano et al., 2010) }\end{array}$ & $1^{*}$ \\
\hline Cytoplasm & 7.3 & $\begin{array}{c}-230 \\
\text { (Jones, 2010) }\end{array}$ & $3^{*}$ \\
\hline Rough ER & 7.3 & $\begin{array}{c}-185 \\
\text { (Hwang et al., 1992) }\end{array}$ & $11^{*}$ \\
\hline Smooth ER & 7.3 & $\begin{array}{c}-160 \\
\text { (Jones, 2010) }\end{array}$ & $23^{*}$ \\
\hline Golgi & $\begin{array}{c}5.0 \\
\text { (Navas et al., } \\
2010)\end{array}$ & -160 & $23^{*}$ \\
\hline Lysosomes & 4.5 & $\begin{array}{c}-160 \\
\text { (Gille and Nohl, } \\
2000)\end{array}$ & $23^{*}$ \\
\hline Pericellular Space & 7.4 & -150 & $\begin{array}{c}30 \\
\text { (Copp et al., 2009) }\end{array}$ \\
\hline Venous Plasma & 7.3 & $\begin{array}{c}-140 \\
\text { (Go and Jones, } \\
2008 \text { ) }\end{array}$ & $\begin{array}{c}40 \\
\text { (West, 2000) }\end{array}$ \\
\hline
\end{tabular}

\#Glutathione Redox potentials vary $10-15 \%$ according to growth conditions in single cells, and vary up to $20 \%$ in different cell types. Plasma redox potentials vary $5-10 \%$ in a diurnal cycle, and become up to $20 \mathrm{mV}$ more oxidizing with age and disease(Go and Jones, 2011).

${ }^{*}$ Estimated from the regression equation: $\log \left(\mathrm{pO}_{2}\right.$ in Torr $)=(\mathrm{mV}$ Redox +272$) \div 82.6$ 


\section{Figure 1}

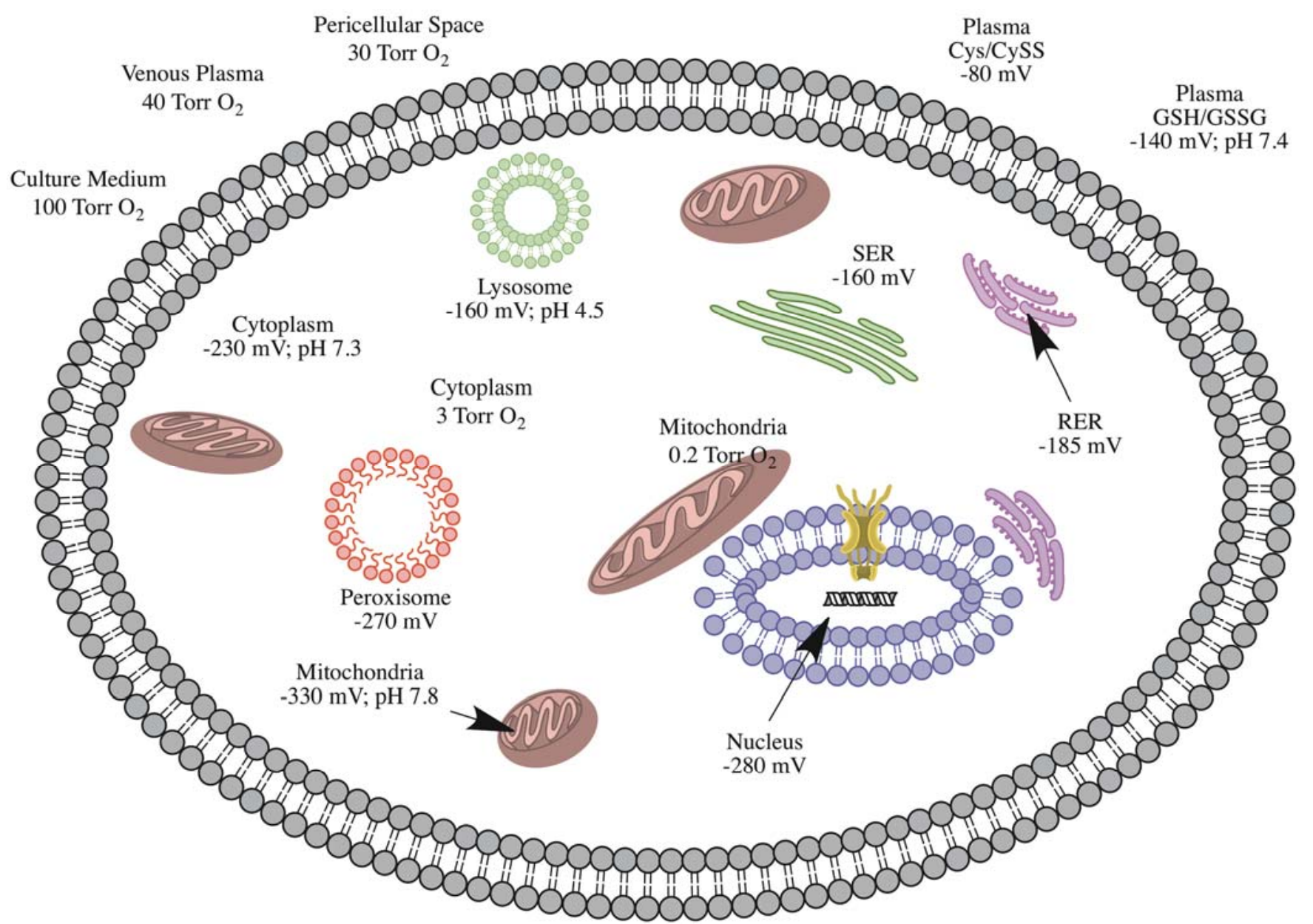




\section{Figure 2A}
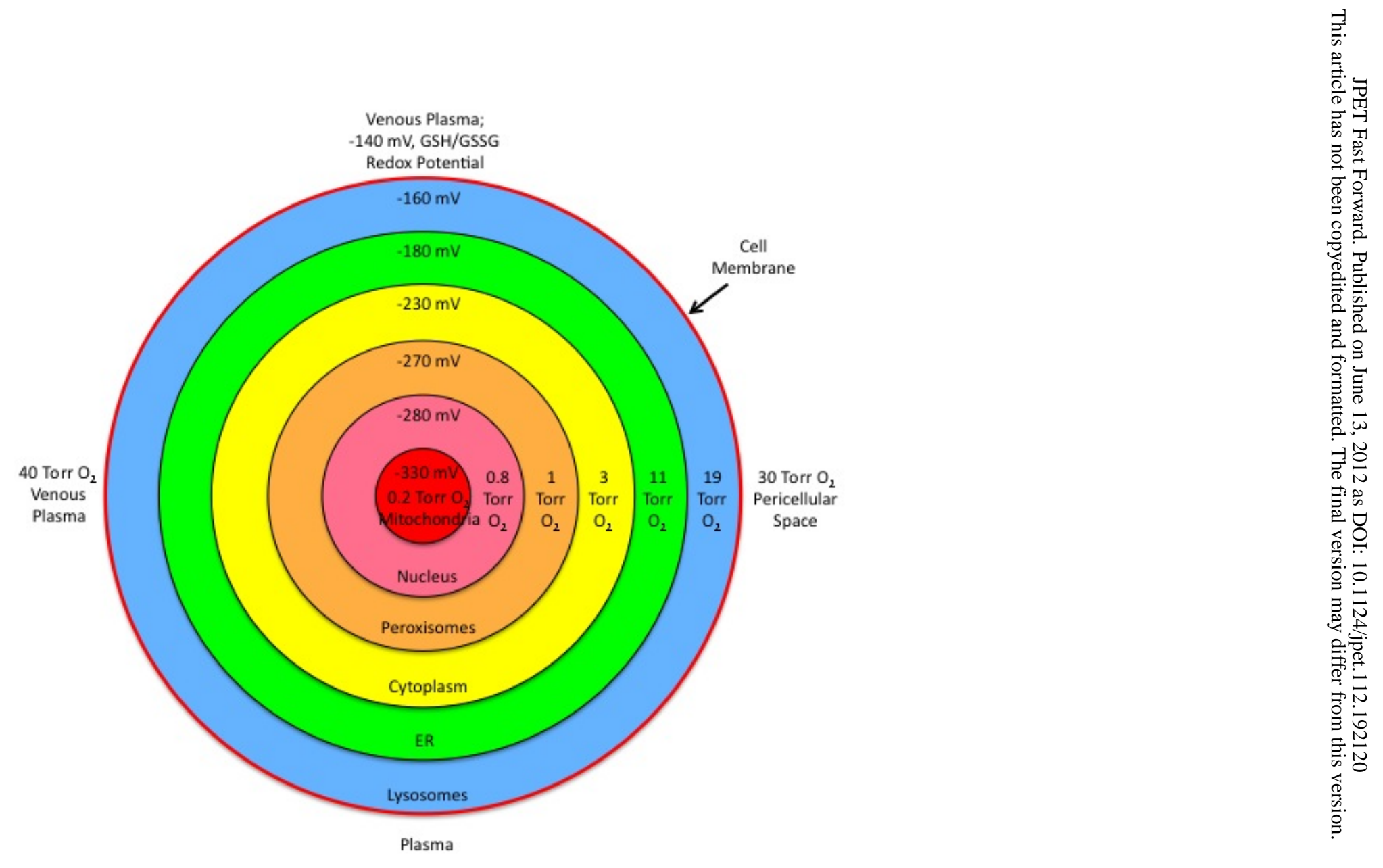


\section{Figure 2B}

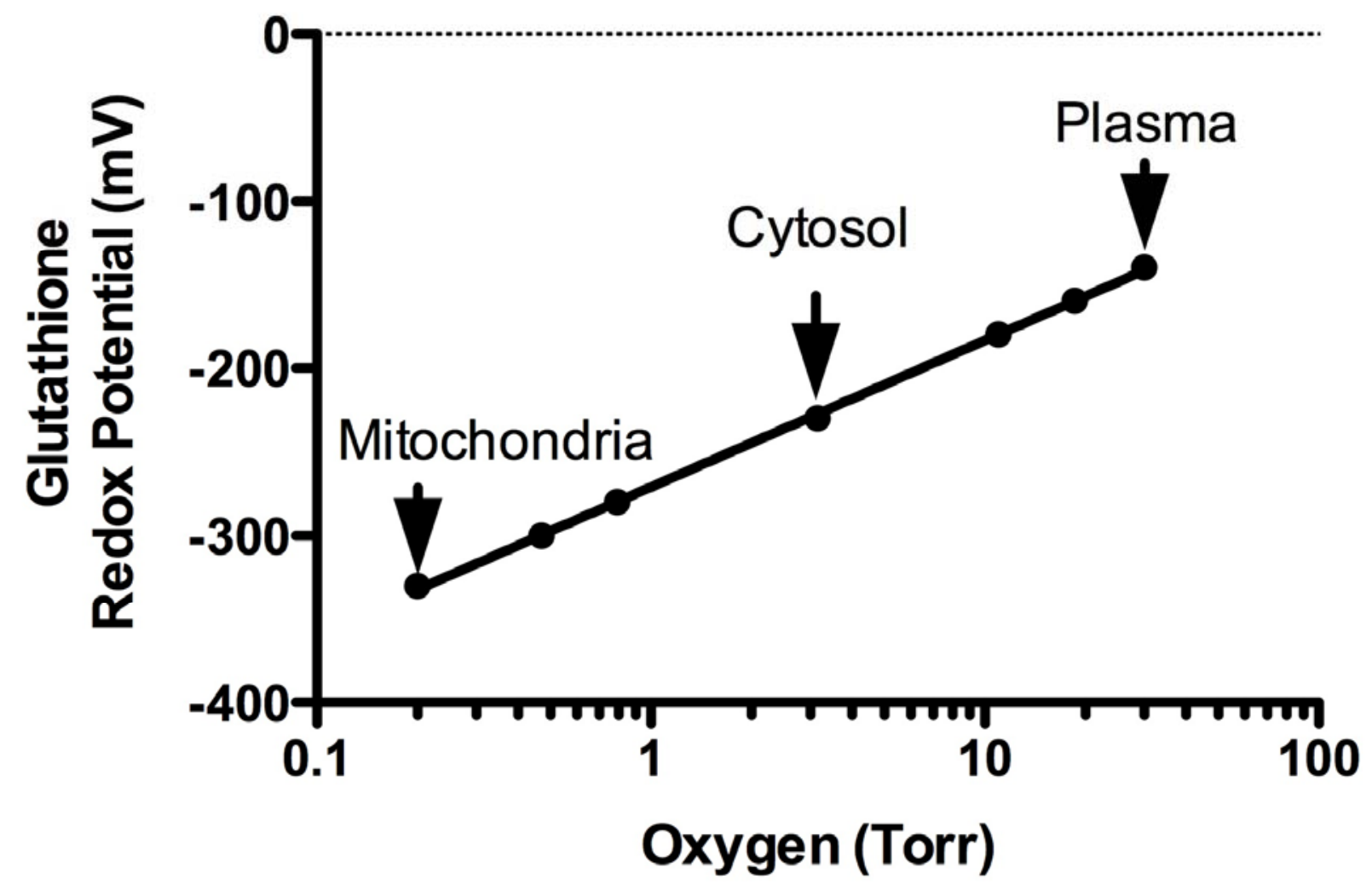




\section{Figure 3}

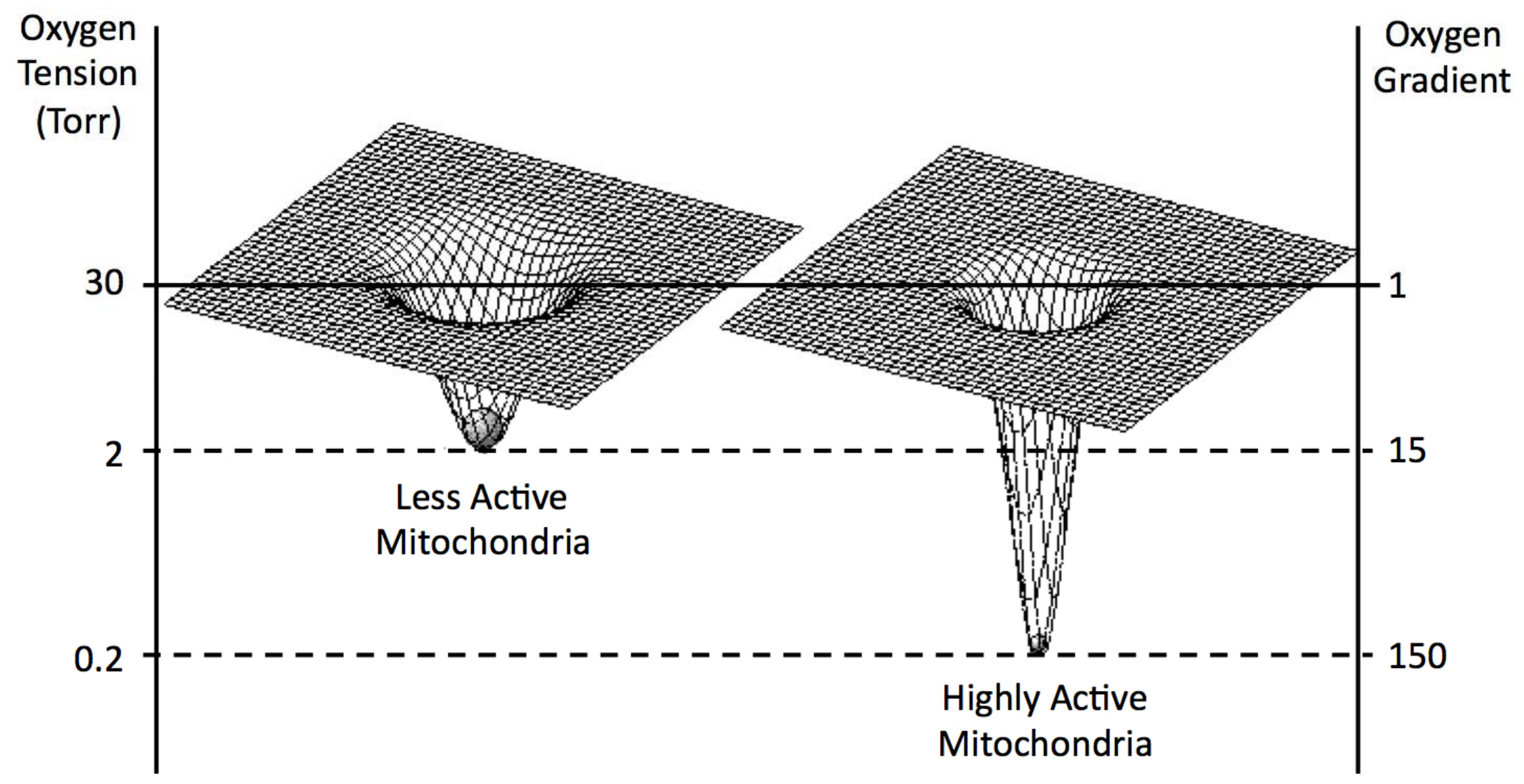

